\title{
Asymmetric Business Cycle Effects on US Sectoral Stock Returns
}

\section{Keran $\mathbf{S}^{*}$ and Prasad VB}

Department of Economics, Florida International University, Miami, Florida, USA

\begin{abstract}
Two models are developed in this paper in order to discuss possible asymmetric business cycle effects on US sectoral stock returns. One is a GARCH model with asymmetric explanatory variables and the other one is an ARCH-M model with asymmetric external regressors. In the second model, square root of conditional variance of the business cycle proxy is characterized as positive or negative risk, depending on the algebraic sign of past innovations driving the business cycle proxy. This helps to capture any asymmetric effects of positive and negative business cycle risk on returns. We find that some sectors change their cyclicities from expansions to recessions. Negative shocks to business cycles have most power to influence sectoral volatilities. Positive and negative parts of business cycle risk have same effects on some sectors but have opposite effects on other sectors. A general conclusion of both models is that business cycles has stronger effects than own sectoral effects in driving sectoral returns.
\end{abstract}

Keywords: Asymmetric business cycle effect; Sectoral stock returns; GARCH; ARCH-M

JEL code: C32, E32, G17

\section{Introduction}

To describe and predict stock return is an interesting but difficult assignment. Though many theories and models devote their contributions to this task, it is still an inconclusive problem. For example, Arbitrage Pricing Theory (APT) assumes that there are $n$ factors which may affect a firm's stock returns. But it does not tell us what these $n$ factors are. Most commonly accepted factors are three factors: dividend yield, default premium, and term premium [1]. However, use a well-established database to demonstrate that, actually, these three factors have power to predict stock returns only because they contain information about business conditions [2]. This result also reinforces, who claim that the default premium and the term premium are qualified to predict stock returns only because they possess business cycle information [3]. For this reason, the business cycle sometimes replaces macroeconomic and financial variables to describe and predict stock returns directly.

There are numerous papers that investigate the business cycle effect on stock returns, but they all concentrate on the whole market. Among those papers, Fama showed that dividend yield, default spread, and term spread are inversely related to business conditions (the business cycle) and positively related to expect stock returns [1]. This implies a negative relationship between stock returns and the business conditions. Similarly, Campbell [2] confirms the same negative relationship using seven different proxies of the business cycle.

An interesting phenomenon is that, although the whole market is negatively related to the business cycle, sectoral stock markets show a mixed co-movement with the business cycle. It is widely accepted that sectoral stock returns behave as pro-cyclical, counter-cyclical, or acyclical. This is equivalent to express that sectoral stock returns are positively related to, negatively related to, and not related to the business cycle. Needless to say, the aggregated market stock index cannot reflect the different relationships between the business cycle and sectoral stock indices. Reasons for distinct reactions of sectors to the business cycle are straightforward. Sectors are composed of different enterprises which will be influenced by many factors, such as organization structures, labor quality, production cost, transaction cost, information transmission channel, sensitivity to macroeconomic variables, and so on. All these factors affect the operation of an enterprise, and make the behavior of the enterprise different from that of others. Discrepancy of operation and behavior among enterprises will finally be reflected in their market value. When we categorize all enterprises into some sectors, the individual specific characteristics will be absorbed by those sectors. This produces two results: first, being a collection of enterprises, a sector shall contain the common properties of its belongings, and reflect these properties in its stock index. Second, each sector will have its own qualities which are different from others' and manifested by the stock index. Hence, sectoral level research is valuable and necessary.

Broadly speaking, research on a specific sector, or some related sectors, can be regarded as sectoral research. Such sectors always have important connections with the whole economy, or reveal very diverse traits compared to other sectors. Among these sectors, financials is the most frequently studied. There is a huge amount of literature that discusses the financial sector and its subsectors, like banks, real estates, insurance companies, and so on $[4,5]$. Besides the financial sector, some real sectors have also been considered, such as high technology sector [6], basic materials [7], oil and gas [8], and a subsector called sin sector, which involves tobacco, alcohol and gaming [9]. Papers mentioned above provide valuable results for sectoral stock returns.

However, for our particular purpose, we need to encompass all sectors. We follow previous literature in classifying the stock market into ten sectors: basic materials, consumer goods, consumer service, financials, health care, industrials, oil and gas, technology, telecommunication, and utility. For simplicity, we abbreviate them to BM, NC, CY, FN, HC, IN, EN, TC, TL, and UT. This classification has been used by Dow Jones Global Index; Thomson Reuters Data stream Sector Index, FTSE Sector Index, and some other major indexes.

Literature in existence has already documented some unique features of different sectors. Arouri investigates effects of crude oil

${ }^{*}$ Corresponding author: Keran Song, PhD Scholar, Department of Economics, Florida International University, USA, Tel: +1 305-348-2000; E-mail: ksong001@fiu.edu

Received September 14, 2015; Accepted September 22, 2015; Published September 28, 2015

Citation: Keran S, Prasad VB (2015) Asymmetric Business Cycle Effects on US Sectoral Stock Returns. Int J Econ Manag Sci 4: 289. doi:10.4172/21626359.1000289

Copyright: ( 2015 Keran S, et al. This is an open-access article distributed under the terms of the Creative Commons Attribution License, which permits unrestricted use, distribution, and reproduction in any medium, provided the original author and source are credited. 
price fluctuations on 12 Europe sectoral stock indices and national index [10]. By broadening the perspective from aggregated level to disaggregated sectoral level, he compares the sensitivity of sectoral stock returns and the whole market returns to oil price changes. Results from this paper show that strength of the association between oil price change and stock returns varies greatly across sectors. Similar works can be found in Arouri [11,12] and Nandha [13], which all pay attention to the relationship between the oil price and sectoral stock returns. There are also some papers that examine the effect of exchange rates on sectoral stock returns that start from three aspects to test the influence of exchange rate exposure on sectoral stock returns in Japan: sensitivity of sectoral returns to changes in exchange rate of the yen; sensitivity of the conditional volatility of sectoral returns to changes in exchange rate of the yen and its possible asymmetric effect; and the correlation between sectoral returns and exchange rate changes [14]. Their results are fruitful in that they present different sensitivities of sectors and distinct time varying processes of correlations between sectors and exchange rate exposure.

One major concern on sectoral stock research is the co-movement of disaggregate market and aggregate market. The direct approach for this consideration is to investigate the relationship between aggregate index and sectoral indexes. For example, Balli [15] introduced ten sectors and some subsectors to test the existence of the structural change effect of the EMU's emergence. They find that the aggregate Euro equity index affects many sectoral indices, especially the financial sector. However, some non-financial sectors, like basic resources, food and beverages, health-care, retail services, oil and gas, and utility show less dependence on the aggregate Euro equity index. Sehgal [16] introduced ten sectoral indices as well as aggregate index, the BSE-500, of Indian stock market to explain the reasons for success of the momentum trading strategy. Their research shows that a large part of stock momentum profits is captured by sectoral factors. They conclude that sectoral momentum accounts for a major part of aggregate momentum.

The co-movement of disaggregate market and aggregate market is closely related to the relationship between sectoral stock returns and the business cycle. The business cycle is a main representation of an economy, which intrinsically relates to the aggregate market behavior. Therefore, the business cycle becomes a good variable to analyze sectoral stock returns. Berdot took the business cycle into consideration and introduced exchange rate to analyze sectoral stock returns [17]. Using French sectoral stock returns and US business cycle data, they inspect exchange rate effects on the sectors. They calculate co-variations between US business cycle and French market sectoral stock returns. Then they estimate significant lags/leads length to the business cycle for each sector. With this information, they classify the French sectoral stock indices as early sectors, lagging sectors, and concurrent sectors. Their final results show that the whole market and the sectoral markets are divergent, and reveal that the aggregate level index may average out different feedbacks of sectoral returns to business conditions $[18,19]$. Above evidence asserts that sectors follow different stochastic processes which cannot be identified by aggregate index data. Early literature has demonstrated that the actual power of explanatory factors stems from their inherent business cycle information. Therefore, in this paper, we follow these previous research results to use the business cycle to explain and predict sectoral stock returns.

We intend to address two issues in discussing business cycle effects on sectoral stock returns. In the first part we want to discern the relationship between the business cycle and sectoral stock returns in two channels simultaneously: business cycle effects on the mean of sectoral stock returns and business cycle shocks' effects on the volatility of sectoral stock returns. Mean and volatility are two major characteristics of stock returns. However, up to now, there is no such research which considers effects of the business cycle on both of them. Thus, one purpose of this paper is to discuss this problem. A GARCH model is developed for this purpose. In the second part, where an ARCH-M model will be applied, we want to detect possible relationships between risk of the business cycle and returns of sectoral indexes. Square root of the conditional variance of the business cycle series will be used as the risk measure which will exert its explanatory power on sectoral stock returns. This square root appears like an "exogenous ARCH term", resembling own ARCH term of sectoral stock returns. We try to use this exogenous term to illustrate the risk-return relationship between the business cycle and sectoral stock returns. Thus, with the first model, we can capture the parallel business cycle effect on the first and second moments of sectoral stock returns, and with the second model, we can capture the cross effect of the second moment of the business cycle on means of sectoral stock returns.

One important consideration is that the impact of the business cycle may be asymmetric. The asymmetry is widely documented and accepted in the literature. For example, comparing sectoral stock indices and US economic peaks and trough from 1973 to present, one can note that stock prices always drop earlier than the business cycle's troughs, excepting the trough in November 2001, while movements of stock prices around the peaks are mixed where a lot of concurrences exist. Therefore, we split the business cycle into positive and negative parts to model this asymmetric impact. A benchmark symmetric model will be set up and evaluated first, and then an asymmetric model will be introduced and estimated. As a result, the asymmetry we mentioned in this paper has two layers: the first is the asymmetric effect of the business cycle on stock returns of different sectors of an economy; the second is the asymmetric effect of the different periods of the business cycle, the expansion and the recession, on sectoral stock returns.

The rest of this paper is organized as follows. Section two elaborates on data issues, mainly regarding the data sources and selection of the proxy for the business cycle; section three sets up the models, namely the symmetric and asymmetric parallel business cycle effect model, and the symmetric and asymmetric cross business cycle effect model; section four provides empirical results; section five concludes.

\section{Data}

According to Federal Reserve Bank's release H.15, annualized discount yield on 3-month Treasury bill is used as interest rate. We use this variable as the risk-free asset return in the paper. All other data are obtained from Data stream. The ten sectors studied along with the abbreviations used to refer to them are summarized in Table 1. We also analyze returns on the aggregate US stock market index. For simplicity, the ten sectors along with the aggregate US market index are referred to as eleven sectors in the rest of this paper.

\begin{tabular}{|l|l|l|l|}
\hline Abbreviation & Full name & Abbreviation & Full name \\
\hline US & US whole market & BM & Basic materials \\
\hline NC & Consumer goods & CY & Consumer service \\
\hline FN & Financials & HC & Health care \\
\hline IN & Industrials & EN & Oil and gas \\
\hline TC & Technology & TL & Telecommunication \\
\hline UT & Utility & & \\
\hline
\end{tabular}

Table 1: Basic sectors and their abbreviations.

The abbreviations for sectors follow the convention of Data Stream 
There are two potential proxies for the business cycle, GDP and Industrial Production. GDP is the most comprehensive, and therefore contains most information about the business cycle. However, it is only measured at a quarterly frequency. This is not suitable for our purposes. Studying quarterly stock returns will not enable us to answer some of the questions being addressed here, such as the business cycle's volatilities effects on sectoral indices' volatilities, and the business cycle's risk effects on sectoral indices' returns. Answering these questions requires us to use models being able to analyze volatilities. High-frequency data with GARCH effects better satisfies our purposes. Therefore, Industrial Production (IP) is chosen as a proxy for the business cycle. It is measured on a monthly basis.

One problem of using IP is that its release date lags behind its occurrence. For example, IP index in January 2014 is released on February 14th. Consequently, January's IP growth rate will affect stock market staring from February 15th. Its effect will end on March 17th when February's IP index is released. This reminds us to calculate monthly stock returns depending on release dates rather than on calendar dates. Table 2 displays release dates of IP index and implied time correspondence between IP and stock market. Our data spans the period from February 1973 through February 2014.

Using information in Table 2, we compute monthly sectoral stock indices $\mathrm{sp}_{\mathrm{t}}$ as an average of daily stock indices over that month (Note, the "month" here is different from the calendar month.) Let $s r_{t}$ denote monthly sectoral stock returns at time $t$. These are obtained as: $\mathrm{sr}_{\mathrm{t}}=\ln$ $\left(\mathrm{sp}_{\mathrm{t}}\right)-\ln \left(\mathrm{sp}_{\mathrm{t}-1}\right)$. Monthly IP growth rate (clearly calendar month) is defined by the same formula. Then, for easier interpretation, monthly $\mathrm{sr}_{\mathrm{t}}$ and IP growth rate are annualized into percent per year. Some main statistics of the variables are summarized in Tables 3 and 4 .

Table 3 displays the minimum and maximum values for returns, along with their dates of occurrences. Two features are worth noting. First, all sectors, excepting TL and UT, have their minima during the stock market crash of 1987 . However, for all other sectors, maxima occur in different months of different years. Second, the range of minima is greater than the range of maxima. The lowest return is -395 percent per year on CY. Other minima range from -394 to -201 . The highest return is 251 on FN. Other maxima range from 135 to 229.

Table 4 displays other main statistics. During the period studied, average return on US whole market is 7 percent per year. Among individual sectors, the highest average return is 9 percent per year on $\mathrm{HC}$ and the lowest is 3.4 on UT. Average returns on NC, TL and UT

\begin{tabular}{|c|c|c|}
\hline IP index release date & Time Period of IP & Time of influenced stock market \\
\hline 1973.1 .15 & 1972.12 & $1973.1 .16-1973.2 .16$ \\
\hline 1973.2 .16 & 1973.1 & $1973.2 .17-1973.3 .16$ \\
\hline 1973.3 .16 & 1973.2 & $1973.3 .17-1973.4 .16$ \\
\hline 1973.4 .16 & 1973.3 & $1973.4 .17-1973.5 .14$ \\
\hline 1973.5 .15 & 1973.4 & $1973.5 .16-1973.6 .14$ \\
\hline$\vdots$ & $\vdots$ & $\vdots$ \\
\hline$\vdots$ & $\vdots$ & $\vdots$ \\
\hline 2013.12 .16 & 2013.11 & $2013.12 .17-2014.1 .17$ \\
\hline 2014.1 .17 & 2013.12 & $2014.1 .18-2014.2 .14$ \\
\hline 2014.3 .14 & 2014.1 & $2014.2 .15-2014.3 .17$ \\
\hline
\end{tabular}

Source of IP index release date: Federal Reserve Bank.

Website: http://www.federalreserve.gov/releases/g17/.

Table 2: Calendar time and corresponding time period in models.

\begin{tabular}{|c|c|c|c|c|}
\hline & Min Occurrence Date & Min Value & Max Occurrence Date & Max Value \\
\hline RUS & $1987.10 .17-1987.11 .16$ & -296.83 & $2009.3 .17-2009.4 .15$ & 135.11 \\
\hline RBM & $1987.10 .17-1987.11 .16$ & -393.91 & $2009.3 .17-2009.4 .15$ & 210.11 \\
\hline RNC & $1987.10 .17-1987.11 .16$ & -371.9 & $1982.10 .16-1982.11 .16$ & 158.35 \\
\hline RCY & $1987.10 .17-1987.11 .16$ & -395.14 & $1975.1 .16-1975.2 .13$ & 175.39 \\
\hline RFN & $1987.10 .17-1987.11 .16$ & -286.48 & $2009.3 .17-2009.4 .15$ & 251.27 \\
\hline RHC & $1987.10 .17-1987.11 .16$ & -260.78 & $1974.10 .16-1974.11 .15$ & 165.19 \\
\hline RIN & $1987.10 .17-1987.11 .16$ & -364.56 & $2001.4 .18-2001.5 .14$ & 167.74 \\
\hline REN & $1987.10 .17-1987.11 .16$ & -275.15 & $1980.1 .17-1980.2 .15$ & 166.94 \\
\hline RTC & $1987.10 .17-1987.11 .16$ & -372.16 & $1975.2 .14-1975.3 .14$ & 204.47 \\
\hline RTL & $2008.9 .16-2008.10 .16$ & -200.73 & $2002.10 .18-2002.11 .15$ & 229.04 \\
\hline RUT & $2009.2 .19-2009.3 .16$ & -210.23 & $1975.1 .16-1975.2 .13$ & 155.97 \\
\hline RIP & $2008.9 .16-2008.10 .16$ & -51.64 & $1998.8 .15-1998.9 .16$ & 25.19 \\
\hline INT & $2011.9 .16-2011.10 .17$ & 0.01 & $1981.5 .16-1981.6 .16$ & 16.3 \\
\hline
\end{tabular}

1. Units of Min and Max values are percent per year.

2. $\mathrm{R}$ denotes returns. For example, RUS denotes stock returns on entire US market index, RBM indicates stock returns on the sector referenced by BM (Basic materials), and so forth. The only exception is RIP, which denotes the growth rate of IP (Industrial production).

3. INT denotes interest rate on 3-month T-bill.

Table 3: Minima and Maxima.

\begin{tabular}{|c|c|c|c|c|c|}
\hline & $(\mathbf{1})$ & $\mathbf{( 2 )}$ & $\mathbf{( 3 )}$ & $\mathbf{( 4 )}$ & $\mathbf{- 5}$ \\
\cline { 2 - 6 } & Mean & Median & Std. & Skewness & Kurtosis \\
\hline RUS & 7 & 12.4 & 46.95 & -1.17 & 7.86 \\
\hline RBM & 6.69 & 11.31 & 65.9 & -1.11 & 8.57 \\
\hline RNC & 4.58 & 10.39 & 57.21 & -1.1 & 7.6 \\
\hline RCY & 7.55 & 12.4 & 58.31 & -1.07 & 8.29 \\
\hline RFN & 7.07 & 12.93 & 61.65 & -0.75 & 6.17 \\
\hline RHC & 8.99 & 11.28 & 46.11 & -0.73 & 6.04 \\
\hline RIN & 8.14 & 14.9 & 58.04 & -1.12 & 7.95 \\
\hline REN & 7.65 & 12.05 & 54.92 & -0.72 & 5.18 \\
\hline RTC & 7.3 & 8.72 & 71.57 & -0.65 & 5.55 \\
\hline RTL & 4.39 & 7.72 & 50.47 & -0.51 & 4.92 \\
\hline RUT & 3.41 & 7.8 & 44.03 & -0.85 & 5.94 \\
\hline RIP & 2.04 & 2.84 & 8.83 & -1.33 & 8.73 \\
\hline INT & 5.15 & 5.09 & 3.4 & 0.51 & 3.37 \\
\hline
\end{tabular}

1. All variables are measured monthly, in percent per year.

2. Annualized discount yield on 3-month Treasury bill, reported in Federal Reserve Bank's release H.15, is used as interest rate.

GARCH model of IP growth rate:

$r_{g t}=c_{g m}+a_{g 1} r_{g t-1}+a_{g 2} r_{g t-2}+a_{g 3} r_{g t-3}+\varepsilon_{g t}, \varepsilon_{g t}=v_{g t} \sqrt{h_{g t}}, v_{g t} \sim$ iid $N(0,1)$

$\mathrm{h}_{\mathrm{gt}}=\mathrm{c}_{\mathrm{gv}}+\mathrm{a}_{\mathrm{g}} \varepsilon_{\mathrm{gt}-1}^{2}+\beta_{\mathrm{g}} \mathrm{h}_{\mathrm{gt}-1}$

GARCH model of sectoral stock returns:

$\mathrm{r}_{\mathrm{it}}=\mathrm{c}_{\mathrm{im}}+\mathrm{a}_{\mathrm{i}} \mathrm{r}_{\mathrm{it}-1}+\mathrm{f}_{\mathrm{i}} \mathrm{r}_{\mathrm{gt}-1}+\varepsilon_{i t}, \varepsilon_{i t}=\mathrm{v}_{\mathrm{it}} \sqrt{\mathrm{h}_{\mathrm{it}}}, \mathrm{v}_{\mathrm{it}} \sim$ iid $\mathrm{N}(0,1)$ and independent of $\mathrm{v}_{\mathrm{gt}}$

$\mathrm{h}_{\mathrm{it}}=\mathrm{c}_{\mathrm{iv}}+\mathrm{a}_{\mathrm{i}} \varepsilon_{\mathrm{it}-1}^{2}+\beta_{\mathrm{i}} \mathrm{h}_{\mathrm{it}-1}+\varphi_{\mathrm{i}} \varepsilon_{\mathrm{gtt}-1}^{2}$

Table 4: Summary Statistics.

are lower than average interest rates, which is 5.2 percent per year. The third column lists standard deviations. Standard deviations of sectoral stock returns are much higher (about 13 times to 21 times) than that of interest rates. Columns 4 and 5 provide skewness and kurtosis of each series. The negative numbers on skewness and large magnitudes on kurtosis tell us that stock returns are left skewed and have higher modes and fatter tails than a normal distribution.

\section{The Econometric Model}

Generally, we can write expected stock returns $\mathrm{E}_{\mathrm{t}-1}\left(\mathrm{r}_{\mathrm{t}}\right)$ as a function of business conditions at time $t-1$ : $E_{t-1}\left(r_{t}\right)=F\left(X_{t-1}\right)$, where $X_{t-1}$ denotes 
business conditions at $\mathrm{t}-1$. This function indicates that, based on the information about business conditions at $\mathrm{t}-1$, investments made at $\mathrm{t}-1$ expect to get returns at $\mathrm{t}$.

Explicit forms of the function and specific variables for $\mathrm{X}_{\mathrm{t}-1}$ vary according to the models. With a focus on asymmetric business cycle effects on sectoral stock returns, we set up two econometric time series models: parallel business cycle effect model and cross business cycle effect model. Different components of the IP growth rate are employed as $\mathrm{X}_{\mathrm{t}-1}$ in these models. Specifically, in the parallel effect model, we use the IP growth rate to explain sector returns and its shocks to explain sector conditional variances. In the cross effect model, we use square root of conditional variance of IP growth rate to explain sector excess returns.

\section{Parallel business cycle effect}

Symmetric parallel business cycle effect: Our major concerns are asymmetric effects. Before discussing asymmetric effects, we set up a symmetric model to reveal the general effect of the business cycle and to provide the basis for evaluating the asymmetric effects. Frameworks of the symmetric model and the asymmetric model are the same. The difference between them is just the component of the explanatory variable $\mathrm{X}_{\mathrm{t}-1}$

With the parallel model we aim at two points: the business cycle's effects on mean of sectoral stock returns, and spillover effects from the business cycle's volatilities to volatilities of sectoral stock returns. A GARCH model enables us to discuss these two problems simultaneously. The first order lag of IP growth rate is included in the mean equation of sectoral stock returns. Though stock returns always have strong tendency to be autoregressive, some other factors may also have powerful explanatory role on the mean of them. Besides, since different sectors are composed of different enterprises, these factors may have distinct effects from sector to sector. By including the lag of IP growth rate, we hope to verify the variation of business cycle effect over sectors' means. Then, the first order lag of squared residuals from auto regression of IP growth rate, which designate shocks to the business cycle, are inserted into the GARCH processes of sectoral stock returns. This can reveal the discrepancy of spillover effects of the business cycle on sectors.

The mean equations of IP growth rate is given by:

$$
r_{g t}=c_{g m}+a_{g 1} r_{g t-1}+a_{g 2} r_{g t-2}+a_{g 3} r_{g t-3}+\varepsilon_{g t}
$$

The subscript $g$ indicates that the parameter is used for growth rate of IP and the subscript $m$ indicates that the parameter is used for mean equation. We assume that IP growth rate is a function of its own lags. Preliminary analysis for the ACF of IP growth rate indicates that the order of autoregressive process should be set to three. The residual of equation $(1) \varepsilon_{\mathrm{gt}}$, is assumed to follow a $\operatorname{GARCH}(1,1)$ process:

$$
\begin{aligned}
& \varepsilon_{g t}=v_{g t} \sqrt{h_{g t}} \\
& h_{g t}=c_{g v}+\alpha_{g} \varepsilon_{g t-1}^{2}+\beta_{g} h_{g t-1}
\end{aligned}
$$

The conditional variance, $h_{g t}$ is described by equation (3). It depends on its own lag and the squared shock from last period. The subscript $v$ indicates the parameter is used for variance equation. $v_{\text {ot }}$ In equation (2) is a white noise process, such that $v_{g t}$ iidN(0.1). Therefore the IP growth rate is an AR $(3)-\operatorname{GARCH}(1,1)$ process.

Equation (4) is the mean equation of sectoral stock returns with symmetric business cycle effect.

$$
r_{i t}=c_{i m}+a_{i} r_{i t-1}+f_{i} r_{g t-1}+\varepsilon_{i t}
$$

We assume that all sectors share the same mean and variance equation. The subscript $i$ indicates different sectors of an economy, which are US, BM, NC, CY, FN, HC, IN, EN, TC, TL, UT ${ }^{1}$. Other subscripts have the same meanings as in previous equations. The parameter $f_{i}$ captures different business cycle effects on each sector. The residuals of the mean equation also follow a $\operatorname{GARCH}(1,1)$ process:

$$
\begin{aligned}
& \varepsilon_{i t}=v_{i t} \sqrt{h_{i t}} \\
& h_{i t}=c_{i v}+\alpha_{i} \varepsilon_{i t-1}^{2}+\beta_{i} h_{i t-1}+\varphi_{i} \varepsilon_{g t-1}^{2}
\end{aligned}
$$

In equation (5), $\mathrm{V}_{\mathrm{it}} \sim$ iid $\mathrm{N}(0,1)$ and is independent of $\mathrm{V}_{\mathrm{gt}}$. The conditional variance of $\varepsilon_{i t}$ depends on its own lag, square of its shock from last period, and the square of business cycle shock from last period. The parameter $\varphi_{\mathrm{i}}$ measures the spillover effect from the business cycle on volatility of each sector. As $\varphi_{\mathrm{i}}$ appears in the variance equation, it must have a positive value. Therefore, we can only compare the different business cycle effects on sectoral stock returns volatility from the magnitude of $\varphi_{\mathrm{i}}$ rather than the sign of it.

Because GARCH process for IP growth rate does not depend on any information of sectoral stock returns, we can first estimate equation (1), (2), and (3) to obtain $\varepsilon_{\mathrm{gt}}$ and $\mathrm{h}_{\mathrm{gt}}$, and then use them to estimate equation (4), (5), and (6). Thus, for this model we just need to estimate two separate GARCH processes.

Asymmetric parallel business cycle effect: Progressing to an asymmetric model, positive and negative portions of the business cycle's mean and variance need to be included in the mean and variance equation of sectoral stock returns, respectively. Developed from the symmetric model, the asymmetric model is as follows.

$$
\begin{aligned}
& r_{g t}=c_{g m}+a_{g 1} r_{g t-1}+a_{g 2} r_{g t-2}+a_{g 3} r_{g t-3}+\varepsilon_{g t} \\
& r_{i t}=c_{i m}+a_{i} r_{i t-1}+f_{i}^{p} r_{g t-1}^{+}+f_{i}^{n} r_{g t-1}^{-} \varepsilon_{i t}
\end{aligned}
$$

Equation (1) is the mean equation of IP growth rate which is exactly the same as the symmetric model. Equation (7) is the mean equation of sectoral stock returns which is a function of its first-order lag and asymmetric business cycle effects. In those subscripts, $p$ indicates that the parameter is used for positive asymmetric term, and $n$ indicates that the parameter is used for negative asymmetric term. The rest subscripts have the same meaning as before. Thus, $f_{i}^{p}$ measures business cycle effects on the sectors in expansions and $f_{i}^{n}$ measures effects in recessions. Both the sign and magnitude of $f_{i}^{p}$ and $f_{i}^{n}$ tell us the asymmetric business cycle effects. The asymmetric term $r_{g t-1}^{+}$ and $r_{g t-1}^{-}$are defined as:

$$
\begin{aligned}
& r_{g t-1}^{+}=\left\{\begin{array}{l}
r_{g t-1}, \text { if } r_{g t-1} \geq 0 \\
0, \text { if } r_{g t-1} \prec 0
\end{array}\right\} \\
& r_{g t-1}^{-}=\left\{\begin{array}{ll}
0, \text { if } r_{g t-1} \geq 0 \\
r_{g t-1}, \text { if } r_{g t-1} \prec 0
\end{array}\right\}
\end{aligned}
$$

The residuals of the mean equations are still assumed to follow GARCH $(1,1)$ processes, namely:

$$
\varepsilon_{g t}=v_{g t} \sqrt{h_{g t}}, \varepsilon_{i t}=v_{i t} \sqrt{h_{i t}}
$$

Where $\mathrm{V}_{\mathrm{it}}, \mathrm{V}_{\mathrm{gt}} \sim$ iid $\mathrm{N}(0,1)$ and $\mathrm{V}_{\text {it }}$ and $\mathrm{V}_{\mathrm{gt}}$ are independent.

The conditional heteroskedasticities are as follows: 


$$
\begin{aligned}
& h_{g t}=c_{g v}+\alpha_{g} \varepsilon_{g t-1}^{2}+\beta_{g} h_{g t-1} \\
& h_{i t}=c_{i v}+\alpha_{i} \varepsilon_{i t-1}^{2}+\beta_{i} h_{i t-1}+\varphi_{i}^{p} \varepsilon_{g t-1}^{2+}+\varphi_{i}^{n} \varepsilon_{g t-1}^{2-}
\end{aligned}
$$

Equation (3) is the same as the previous model. Equation (8) is the variance equation of sectoral stock returns. The asymmetric term $\varepsilon_{g t-1}^{2+}$ and $\varepsilon_{g t-1}^{2-}$ are defined as:

$$
\begin{aligned}
& \varepsilon_{g t-1}^{2+}=\left\{\begin{array}{l}
\varepsilon_{g t-1}^{2}, \text { if } \varepsilon_{g t-1} \geq 0 \\
0, \quad \text { if } \varepsilon_{g t-1} \prec 0
\end{array}\right\} \\
& \varepsilon_{g t-1}^{2-}=\left\{\begin{array}{ll}
0, \text { if } \varepsilon_{g t-1} \geq 0 \\
\varepsilon_{g t-1}^{2}, \text { if } \varepsilon_{g t-1} \prec 0
\end{array}\right\}
\end{aligned}
$$

Adding these two ARCH terms into the variance equation of sectoral stock returns can help us to detect possible asymmetric spillover effects of business cycle shocks. However, since the parameters $\varphi_{i}^{p}$ and $\varphi_{i}^{n}$ are both positive, we can only compare the asymmetric effect from their magnitudes.

Estimation strategy is the same as in the symmetric model.

\section{Cross business cycle effect}

Symmetric cross business cycle effect: ARCH-M model provides a good environment to comprehend the relationship between risk and return Holt [20] introduce a multivariate generalized ARCH-M model to identify the feasible endogenous risk of US broiler industry under the CCC-GARCH framework developed a VAR-GARCH-M model to verify possible feedback of exchange rates on their returns among US, Germany, and Japan [21]. For our specific purpose, the second target of this paper is to find the effects of business cycle risk on sectoral stock returns.

The mean equation and the variance equation for the IP growth rate remain the same:

$$
\begin{aligned}
& r_{g t}=c_{g m}+a_{g 1} r_{g t-1}+a_{g 2} r_{g t-2}+a_{g 3} r_{g t-3}+\varepsilon_{g t} \\
& \varepsilon_{g t}=v_{g t} \sqrt{h_{g t}} \\
& h_{g t}=c_{g v}+\alpha_{g} \varepsilon_{g t-1}^{2}+\beta_{g} h_{g t-1}
\end{aligned}
$$

The new mean equation and variance equation for sectoral stock returns are:

$$
\begin{aligned}
& r_{i t}=c_{i m}+\theta_{i} \sqrt{h_{i t}}+\delta_{i} \sqrt{h_{g t}}+\varepsilon_{i t} \\
& \varepsilon_{i t}=v_{i t} \sqrt{h_{i t}} \\
& h_{i t}=c_{i v}+\alpha_{i} \varepsilon_{i t-1}^{2}+\beta_{i} h_{i t-1}
\end{aligned}
$$

The residuals follow GARCH $(1,1)$ processes, where $\mathrm{V}_{\mathrm{it}}, \mathrm{V}_{\mathrm{gt}} \sim$ iid $\mathrm{N}(0,1)$ and $\mathrm{V}_{\mathrm{it}}$, and $\mathrm{V}_{\mathrm{gt}}$ are independent. In the mean equation (9), the left hand side is the excess returns of a sectoral index. The excess return is calculated by subtracting the risk-free asset return from the sectoral stock returns. Here we use the monthly interest rate of the three month Treasury bill as the risk free asset return. On the right hand side, there are two risk factors: one is the risk of the sectoral index itself indicated by square root of its own conditional variance; the other one is the risk of the business cycle indicated by square root of the conditional variance of IP growth rate. Therefore, we can investigate the risk premium of a sectoral index under its own risk and risk of the business cycle.
Asymmetric cross business cycle effect: To explore potential asymmetric effects of good and bad news about the business cycle on the means of sectoral stock indices, we construct another model based on the previous one. The new mean equation for sectoral stock returns is:

$r_{i t}=c_{i m}+\theta_{i} \sqrt{h_{i t}}+\delta_{i}^{p}{\sqrt{h_{g t}}+}^{+}+\delta_{i}^{n}{\sqrt{h_{g t}^{-}}}^{-} \varepsilon_{i t}$

The asymmetric terms ${\sqrt{h_{g t}}}^{+}$and ${\sqrt{h_{g t}}}^{-}$are defined as follows:

$$
\begin{aligned}
& {\sqrt{h_{g t}}}^{+}=\left\{\begin{array}{l}
\sqrt{h_{g t}}, \text { if } \varepsilon_{g t-1} \geq 0 \\
0, \text { if } \varepsilon_{g t-1} \prec 0
\end{array}\right\} \\
& {\sqrt{h_{g t}}}^{-}=\left\{\begin{array}{ll}
0, & \text { if } \varepsilon_{g t-1} \geq 0 \\
\sqrt{h_{g t}}, & \text { if } \varepsilon_{g t-1} \prec 0
\end{array}\right\}
\end{aligned}
$$

The parameters $\delta_{i}^{p}$ and $\delta_{i}^{n}$ can help us capture the positive and negative business cycle risk effects on the mean of sectoral stock returns. Because these two parameters are not constrained to be positive, both their signs and magnitudes will show asymmetric effects of the business cycle. The conditional variance of sectoral stock returns is still a $\operatorname{GARCH}(1,1)$ process and is the same as equation (10):

$$
h_{i t}=c_{i v}+\alpha_{i} \varepsilon_{i t-1}^{2}+\beta_{i} h_{i t-1}
$$

\section{Empirical Results}

\section{Results for symmetric parallel business cycle effect}

Estimation results of the symmetric parallel business cycle effect model are summarized in Table 5. Estimated parameters for monthly growth rate of IP are at the bottom of the table. It is clear that $r_{g t}$ follows a significant AR (3)-GARCH $(1,1)$ process. All three lags have positive effects. The ARCH parameter is slightly bigger than the GARCH parameter showing that exogenous shocks affect IP growth rate to some extent but these effects do not persist for long.

Columns 1 to 3 in Table 5 are estimates of the parameters in equation (4). All intercepts and the first order autoregressive terms are significant. Slopes of the first order lags are comparatively stable: through all sectors, the slopes range from 0.149 to 0.315 . But effects of IP growth rate vary from sector to sector. Two points are worth noting. First, all sectors bear a positive relationship with IP growth rate. This means all sectors are pro-cyclical. Second, for all sectors but NC, parameter for IP growth rate is bigger than that for sector's own lag. The biggest difference between these two parameters is on EN, where IP growth rate brings 4.9 times more changes than EN's own effect. This is especially important for US, IN, EN and UT whose parameters are significant. We can learn from this result that business cycle effects are consistently stronger than sectors' autoregressive effects.

Columns 4 to 7 in Table 5 are estimates of the parameters in equation (6). ARCH effect and $\mathrm{GARCH}$ effect are significant for all sectors. Their parameters lie in 0.092 on EN to 0.443 on NC and in 0.167 on NC to 0.861 on EN. Most sectors, like BM, HC, IN, EN, TC, TL, and UT, have a small ARCH parameter and a large GARCH parameter. For these sectors, a temporary shock from last period has a small effect on current conditional variance, but this small effect will last for a long time. Sector NC has a large ARCH parameter and a small GARCH parameter. Thus, past shocks to NC have important but short effects on its current conditional variance.

The last column of Table 5 discloses the impact of IP growth rate 
Citation: Keran S, Prasad VB (2015) Asymmetric Business Cycle Effects on US Sectoral Stock Returns. Int J Econ Manag Sci 4: 289. doi:10.4172/21626359.1000289

Page 6 of 13

\begin{tabular}{|c|c|c|c|c|c|c|c|}
\hline & (1) & (2) & (3) & (4) & (5) & (6) & (7) \\
\hline & $\mathrm{C}_{\mathrm{im}}$ & $a_{i}$ & $f_{i}$ & $c_{i v}$ & $\alpha_{i}$ & $\beta_{i}$ & $\varphi_{\mathrm{i}}$ \\
\hline \multirow[t]{2}{*}{ RUS } & $8.996^{*}$ & $0.258^{*}$ & $0.46^{*}$ & 199.144 & $0.264^{*}$ & $0.674^{*}$ & 0 \\
\hline & -2.429 & -0.051 & -0.254 & -129.908 & -0.093 & -0.121 & -0.617 \\
\hline \multirow[t]{2}{*}{ RBM } & $6.894^{*}$ & $0.203^{*}$ & 0.218 & $332.903^{*}$ & $0.101^{*}$ & $0.82^{*}$ & 0 \\
\hline & -3.532 & -0.05 & -0.374 & -166.476 & -0.035 & -0.053 & -0.965 \\
\hline \multirow[t]{2}{*}{ RNC } & $9.244^{*}$ & $0.304^{*}$ & 0.297 & $1236.438^{*}$ & $0.443^{*}$ & $0.167^{*}$ & 0.987 \\
\hline & -2.998 & -0.048 & -0.288 & -252.436 & -0.089 & -0.099 & -1.328 \\
\hline \multirow[t]{2}{*}{ RCY } & $10.962^{*}$ & $0.315^{*}$ & 0.41 & $557.717^{*}$ & $0.358^{*}$ & $0.49^{*}$ & 0.69 \\
\hline & -3.017 & -0.048 & -0.307 & -267.061 & -0.08 & -0.132 & -1.233 \\
\hline \multirow[t]{2}{*}{ RFN } & $11.334^{*}$ & $0.287^{*}$ & 0.34 & $537.068^{*}$ & $0.336^{*}$ & $0.517^{\star}$ & 0.946 \\
\hline & -3.043 & -0.047 & -0.305 & -215.065 & -0.087 & -0.114 & -1.096 \\
\hline \multirow[t]{2}{*}{ RHC } & $9.032^{*}$ & $0.262^{*}$ & 0.336 & 146.899 & $0.096^{*}$ & $0.831^{*}$ & 0 \\
\hline & -2.638 & -0.046 & -0.246 & -94.774 & -0.034 & -0.067 & -0.356 \\
\hline \multirow[t]{2}{*}{ RIN } & $9.719^{*}$ & $0.236^{*}$ & $0.578^{*}$ & $358.381^{*}$ & $0.183^{*}$ & $0.717^{*}$ & 0.141 \\
\hline & -3.069 & -0.05 & -0.325 & -209.993 & -0.071 & -0.106 & -0.781 \\
\hline \multirow[t]{2}{*}{ REN } & $6.507^{\star}$ & $0.149^{*}$ & $0.728^{*}$ & $140.552^{*}$ & $0.092^{*}$ & $0.861^{*}$ & 0 \\
\hline & -2.764 & -0.049 & -0.303 & -74.749 & -0.029 & -0.04 & -0.694 \\
\hline \multirow[t]{2}{*}{ RTC } & $8.328^{*}$ & $0.246^{*}$ & 0.397 & $285.381^{*}$ & $0.11^{*}$ & $0.831^{*}$ & 0 \\
\hline & -3.769 & -0.048 & -0.36 & -118.017 & -0.03 & -0.041 & -0.751 \\
\hline \multirow[t]{2}{*}{ RTL } & $4.853^{*}$ & $0.202^{*}$ & 0.32 & $117.321^{*}$ & $0.125^{\star}$ & $0.826^{*}$ & 0 \\
\hline & -2.495 & -0.049 & -0.247 & -48.61 & -0.03 & -0.037 & -0.431 \\
\hline \multirow[t]{3}{*}{ RUT } & $4.465^{*}$ & $0.23^{*}$ & $0.545^{*}$ & $101.572^{*}$ & $0.161^{*}$ & $0.776^{\star}$ & 0.259 \\
\hline & -2.169 & -0.049 & -0.226 & -39.893 & -0.036 & -0.041 & -0.392 \\
\hline & $\mathrm{c}_{\mathrm{ipm}}$ & $\alpha_{i p 1}$ & $\alpha_{\mathrm{ip} 2}$ & $\alpha_{i p 3}$ & $\mathrm{c}_{\mathrm{ipv}}$ & $\alpha_{i p}$ & $\beta_{\text {ip }}$ \\
\hline \multirow[t]{2}{*}{ RIP } & $2.957^{*}$ & $0.172^{*}$ & $0.141^{*}$ & $0.171^{*}$ & $29.11^{*}$ & $0.321^{*}$ & 0.218 \\
\hline & -0.598 & -0.059 & -0.05 & -0.045 & -6.689 & -0.079 & -0.132 \\
\hline \multicolumn{8}{|c|}{ Significance level: 0.1 ‘*’ } \\
\hline
\end{tabular}

Numbers in braces are standard deviations. Some estimates are displayed as 0 since they are smaller than 0.00001 .

GARCH model of IP growth rate:

$\mathrm{r}_{\mathrm{gt}}=\mathrm{c}_{\mathrm{gm}}+\mathrm{a}_{\mathrm{g} 1} \mathrm{r}_{\mathrm{gt}-1}+\mathrm{a}_{\mathrm{g} 2} \mathrm{r}_{\mathrm{gt}-2}+\mathrm{a}_{\mathrm{g} 3} \mathrm{r}_{\mathrm{gt}-3}+\varepsilon_{\mathrm{gt}}, \varepsilon_{\mathrm{gt}}=\mathrm{v}_{\mathrm{gt}} \sqrt{\mathrm{h}_{\mathrm{gt}}}, \mathrm{v}_{\mathrm{gt}} \sim \mathrm{iid} \mathrm{N}(0,1)$

$\mathrm{h}_{\mathrm{gt}}=\mathrm{c}_{\mathrm{gv}}+\mathrm{a}_{\mathrm{g}} \varepsilon_{\mathrm{gt}-1}^{2}+\beta_{\mathrm{g}} \mathrm{h}_{\mathrm{gt}-1}$

GARCH model of sectoral stock returns:

$\mathrm{r}_{\mathrm{it}}=\mathrm{c}_{\mathrm{im}}+\mathrm{a}_{\mathrm{i}} \mathrm{r}_{\mathrm{it}-1}+\mathrm{f}_{\mathrm{i}}^{\mathrm{p}} \mathrm{r}_{\mathrm{gt}-1}^{+}+\mathrm{f}_{\mathrm{i}}^{\mathrm{n}} \mathrm{r}_{\mathrm{gt}-1}^{-}+\varepsilon_{\mathrm{it}}$

$\varepsilon_{\mathrm{it}}=\mathrm{v}_{\mathrm{it}} \sqrt{\mathrm{h}_{\mathrm{it}}}, \mathrm{v}_{\mathrm{it}} \sim$ iid $\mathrm{N}(0,1)$ and independent of $\mathrm{v}_{\mathrm{gt}}$

$\mathrm{h}_{\mathrm{it}}=\mathrm{c}_{\mathrm{iv}}+\alpha_{\mathrm{i}} \varepsilon_{\mathrm{it}-1}^{2}+\beta_{\mathrm{i}} \mathrm{h}_{\mathrm{it}-1}+\varphi_{\mathrm{i}}^{\mathrm{p}} \varepsilon_{\mathrm{gt}-1}^{2+}+\varphi_{\mathrm{i}}^{\mathrm{n}} \varepsilon_{\mathrm{gt}-1}^{2-}$

Table 5: Estimation results of symmetric parallel business cycle effect model.

shocks on volatilities of sectoral stock returns. IP growth rate shocks almost do not affect volatilities of US, BM, HC, EN, TC, and TL. The estimated parameters for these sectors are displayed as 0s since they are smaller than 0.00001 . However, for other sectors, IP growth rate shocks disturb their stability even more than their own shocks do. For example, one unit of shock to IP growth rate increases NC's volatility by 0.987 times and FN's volatility by 0.946 times, while one unit of shock to NC and FN only increases their volatility by 0.443 times and 0.336 times.

From above we can see that first order and second order moment of the business cycle have different effects over sectoral stock returns, and the differences are large from sector to sector.

\section{Results for Asymmetric parallel business cycle effect}

Table 6 summarizes the estimated parameters of the asymmetric parallel business cycle effect model. Parameters of sectors' own factors are listed in columns 1-2 and columns 5-7. These estimation results almost replicate the results of the symmetric effect model. First, the autoregressive terms and the intercepts tend to have same algebraic signs and similar magnitudes, especially so for the autoregressive terms. The maximum AR parameter is 0.315 which occurs for sector $\mathrm{CY}$ and the minimum is 0.145 which occurs for sector EN. Second, the $\mathrm{ARCH}$ parameters and the GARCH parameters follow the pattern in previous model. For most sectors, effects of temporary shocks are small but last for a long time. While for NC, effects of shocks are strong but vanish quickly.

Columns 3 and 4 are estimated parameters for the asymmetric business cycle effects on means of sectoral stock returns. Generally, negative business cycle effects are stronger than positive ones. The smallest parameter for negative effects is 0.579 on $\mathrm{BM}$ while the largest 


\begin{tabular}{|c|c|c|c|c|c|c|c|c|c|}
\hline & (1) & (2) & (3) & (4) & (5) & (6) & (7) & (8) & (9) \\
\hline & $C_{i m}$ & $\alpha_{i}$ & $f^{p}$ & $f_{i}^{n}$ & $c_{i v}$ & $\alpha_{i}$ & $\boldsymbol{\beta}_{i}$ & $\varphi_{i}$ & $\varphi_{\mathrm{i}}$ \\
\hline \multirow[t]{2}{*}{ RUS } & $10.916^{*}$ & $0.262^{*}$ & 0.141 & $0.951^{*}$ & 174.918 & $0.25^{\star}$ & $0.698^{*}$ & 0 & 0 \\
\hline & -3.034 & -0.051 & -0.399 & -0.524 & -138.952 & -0.095 & -0.128 & -0.994 & -0.933 \\
\hline \multirow[t]{2}{*}{ RBM } & $8.579^{*}$ & $0.206^{*}$ & -0.031 & 0.579 & $320.933^{*}$ & $0.1^{*}$ & $0.824^{*}$ & 0 & 0 \\
\hline & -4.576 & -0.05 & -0.58 & -0.763 & -184.073 & -0.04 & -0.052 & -2.045 & -1.282 \\
\hline \multirow[t]{2}{*}{ RNC } & $10.428^{*}$ & $0.305^{*}$ & 0.159 & 0.58 & $1235.3^{*}$ & $0.451^{*}$ & $0.183^{*}$ & 0 & 0 \\
\hline & -3.848 & -0.049 & -0.434 & -0.593 & -265.368 & -0.09 & -0.104 & -1.454 & -0.354 \\
\hline \multirow[t]{2}{*}{ RCY } & $12.272^{*}$ & $0.315^{*}$ & 0.235 & 0.741 & $552.493^{*}$ & $0.349^{*}$ & $0.485^{*}$ & 0 & 2.636 \\
\hline & -3.865 & -0.049 & -0.465 & -0.711 & -287.265 & -0.079 & -0.142 & -1.639 & -2.294 \\
\hline \multirow[t]{2}{*}{ RFN } & $12.238^{*}$ & $0.288^{*}$ & 0.199 & 0.625 & $537.127^{*}$ & $0.327^{*}$ & $0.522^{*}$ & 0.533 & 1.473 \\
\hline & -3.878 & -0.047 & -0.466 & -0.678 & -225.313 & -0.09 & -0.12 & -1.766 & -1.806 \\
\hline \multirow[t]{2}{*}{ RHC } & $11.082^{*}$ & $0.264^{*}$ & 0.031 & 0.735 & 152.037 & $0.093^{*}$ & $0.826^{*}$ & 0 & 0.253 \\
\hline & -3.432 & -0.047 & -0.4 & -0.496 & -101.034 & -0.036 & -0.073 & -0.79 & -0.6 \\
\hline \multirow[t]{2}{*}{ RIN } & $11.145^{*}$ & $0.235^{*}$ & 0.308 & 0.955 & 334.239 & $0.161^{*}$ & $0.737^{*}$ & 0 & 0.744 \\
\hline & -3.976 & -0.051 & -0.536 & -0.679 & -210.328 & -0.07 & -0.101 & -1.492 & -1.415 \\
\hline \multirow[t]{2}{*}{ REN } & $9.154^{*}$ & $0.145^{*}$ & 0.335 & $1.272^{*}$ & $138.508^{*}$ & $0.093^{*}$ & $0.861^{*}$ & 0 & 0 \\
\hline & -3.72 & -0.049 & -0.483 & -0.598 & -79.907 & -0.031 & -0.039 & -1.427 & -0.907 \\
\hline \multirow[t]{2}{*}{ RTC } & $11.307^{*}$ & $0.249^{*}$ & -0.038 & 0.906 & $276.98^{*}$ & $0.108^{*}$ & $0.834^{*}$ & 0 & 0 \\
\hline & -4.999 & -0.048 & -0.599 & -0.675 & -117.866 & -0.031 & -0.04 & -1.627 & -0.873 \\
\hline \multirow[t]{2}{*}{ RTL } & $7.38^{*}$ & $0.201^{*}$ & -0.025 & 0.801 & $118.557^{*}$ & $0.126^{*}$ & $0.825^{*}$ & 0 & 0 \\
\hline & -3.319 & -0.049 & -0.386 & -0.492 & -49.664 & -0.031 & -0.037 & -1.067 & -0.686 \\
\hline \multirow[t]{2}{*}{ RUT } & $7.783^{*}$ & $0.234^{*}$ & 0.123 & $1.391^{*}$ & $101.061^{*}$ & $0.168^{*}$ & $0.779^{*}$ & 0 & 0 \\
\hline & -2.862 & -0.049 & -0.326 & -0.539 & -40.79 & -0.038 & -0.039 & -0.781 & -0.394 \\
\hline \multicolumn{10}{|c|}{ 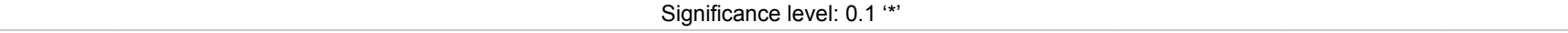 } \\
\hline
\end{tabular}

Note: 1 . Numbers in braces are standard deviations. Some estimates are displayed as 0 since they are smaller than 0.00001.

2. Estimation results of IP growth rate are the same as in symmetric parallel model and therefore are not listed here.

GARCH model of IP growth rate:

$\mathrm{r}_{\mathrm{gt}}=\mathrm{c}_{\mathrm{gm}}+\mathrm{a}_{\mathrm{g} 1} \mathrm{r}_{\mathrm{gt}-1}+\mathrm{a}_{\mathrm{g} 2} \mathrm{r}_{\mathrm{gt}-2}+\mathrm{a}_{\mathrm{g} 3} \mathrm{r}_{\mathrm{gt}-3}+\varepsilon_{\mathrm{gt}}, \varepsilon_{\mathrm{gt}}=\mathrm{v}_{\mathrm{gt}} \sqrt{\mathrm{h}_{\mathrm{gt}}}, \mathrm{v}_{\mathrm{gt}} \sim \mathrm{iid} \mathrm{N}(0,1)$

$\mathrm{h}_{\mathrm{gt}}=\mathrm{c}_{\mathrm{gv}}+\mathrm{a}_{\mathrm{g}} \varepsilon_{\mathrm{gt}-1}^{2}+\beta_{\mathrm{g}} \mathrm{h}_{\mathrm{gt}-1}$

GARCH model of sectoral stock returns:

$\mathrm{r}_{\mathrm{it}}=\mathrm{c}_{\mathrm{im}}+\theta_{\mathrm{i}} \sqrt{\mathrm{h}_{\mathrm{it}}}+\delta_{\mathrm{i}} \sqrt{\mathrm{h}_{\mathrm{gt}}}+\varepsilon_{\mathrm{it}}, \varepsilon_{\mathrm{it}}=\mathrm{v}_{\mathrm{it}} \sqrt{\mathrm{h}_{\mathrm{it}}}, \mathrm{v}_{\mathrm{it}} \sim$ iid $\mathrm{N}(0,1)$ and independent of $\mathrm{v}_{\mathrm{gt}}$

$\mathrm{h}_{\mathrm{it}}=\mathrm{c}_{\mathrm{iv}}+\mathrm{a}_{\mathrm{i}} \varepsilon_{\mathrm{it}-1}^{2}+\beta_{\mathrm{i}} \mathrm{h}_{\mathrm{it}-1}$

Table 6: Estimation results of asymmetric parallel business cycle effect model.

parameter for positive effects is 0.335 on EN. This is a sound proof that business cycle effects are asymmetric. This can also explain the phenomenon why stock market crashes rapidly during depressions but flourishes moderately during expansions. Besides, negative business cycle effects are even stronger than the business cycle effects in symmetric model. This is true for all sectors, referring to Table 5. Obviously, symmetric model will underestimate business cycle effects.

Comparing to sectors' own lag effects, negative business cycle effects are greater. Parameters for autoregressive terms range from 0.145 on EN to 0.315 on CY, while the smallest parameter for negative business cycle effects is 0.579 . On the other hand, positive business cycle effects are greater for only two sectors, IN and EN. As a consequence, sectoral stock returns flourish during expansions mainly based on their own momentum, but they are impaired primarily by the force of business cycle during depressions.

Though all sectors have a positive parameter for symmetric business cycle effect, BM, TC, and TL has a negative parameter for positive business cycle effect. This reveals two categories of cyclical behavior of sectors, which is invisible under symmetric model: consistent behavior and reverse behavior. Sectors like US, NC, CY, FN, HC, IN,
EN, and UT follow consistent behavior: they are pro-cyclical no matter during an expansion or a depression. Sectors like BM, TC, and TL follow reverse behavior: they are counter cyclical during an expansion and pro-cyclical during a depression. This conclusion provides more accurate prediction for stock returns given that business conditions is already known.

Figure 1 compares observed values of sectoral stock returns and their fitted values from the asymmetric parallel model. The pink solid curves and the black dotted curves indicate them, respectively. The figure shows that our model can predict stock returns to some extent. Since our model has a first order autoregressive term in the mean equation of sectoral stock returns, we use Figure 2 to compare fitted values between AR (1) model and our model. The gold solid curves are one step ahead forecast by AR (1). We still use the black dotted curves to indicate the one step ahead forecast by our model. Figure 2 shows that, for extreme values, our model has better forecast than AR (1). For example, our forecasts go deeper around troughs of 1974 and 2009, which are much closer to observed values than forecasts of AR (1). For EN and UT, our forecasts are constantly closer to observed values through the observation period. For NC and $\mathrm{CY}$, the positive 

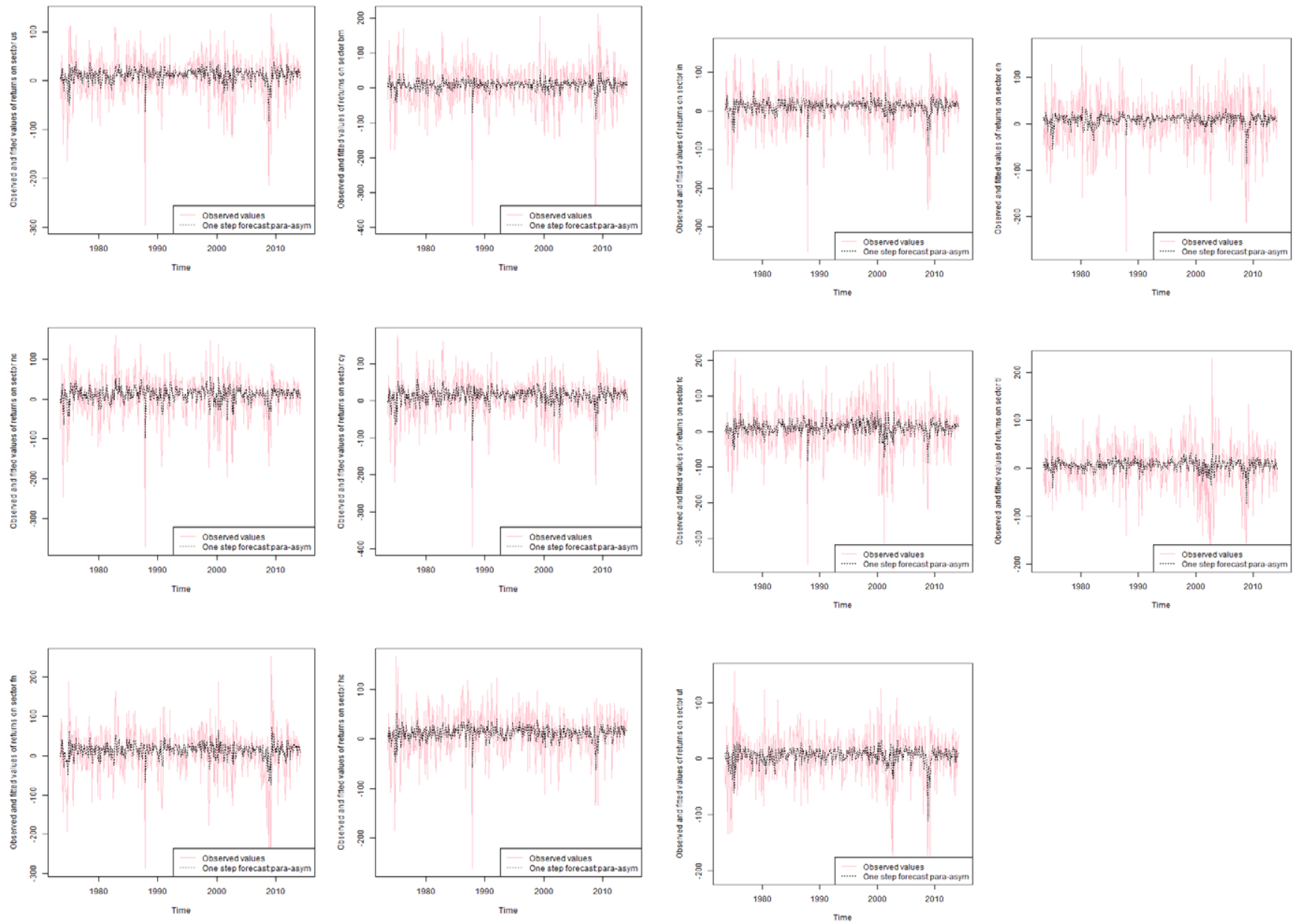

Figure 1: Observed sectoral stock returns and their fitted values from parallel asymmetric model.

part of our forecasts approaches nearer to observed values. For other sectors, there is no obvious difference between our model and AR (1), excluding the mentioned extreme values.

Columns 8 and 9 are estimated parameters for asymmetric business cycle effects on volatilities of sectoral stock returns. As in the symmetric model, some estimates are smaller than 0.00001 and displayed as 0 . Combining the estimation results from symmetric model, the sectors can be distinguished as four groups. For the first one, shocks to business cycle do not have spillover effects on them under both symmetric and asymmetric settings. US, BM, EN, TC, and TL fall into this group. For the second one, shocks to business cycle only have spillover effects in the symmetric model. This group contains UT and NC. For the third one, spillover effects only emerge in the asymmetric model, especially the negative side of the asymmetry. HC is the unique sector in this group. For the last one, spillover effects exist in both models. Rest sectors, CY, FN, and IN are in this group. Among these three, FN is the sole sector which is affected by both positive and negative shocks. CY and IN are affected unilaterally by negative shocks.

The most sensitive spillover effect occurs on CY. The parameter for negative shocks to the business cycle is 2.636 on $\mathrm{CY}$, comparing to 1.476 on FN, 0.253 on $\mathrm{HC}, 0.744$ on IN, and 0.533 on $\mathrm{FN}$ for positive shocks. Same as the symmetric model, external shocks have stronger impact than sector's own shocks. Parameters for ARCH terms are 0.349 on CY, 0.327 on FN, 0.093 on HC, and 0.161 on IN. All of them are smaller than the parameters for their corresponding external shocks. Moreover, since the GARCH parameters of these sectors are large, these external effects will last for a long time.

Figure 3 illustrates relationship between sectoral stock returns and asymmetric shocks to IP growth rate. Red dotted curves indicate sectoral volatilities. Gold solid curves and black solid curves are squared positive shocks and squared negative shocks, respectively. For easy viewing, we mirror squared negative shocks to the opposite direction. But keep in mind that their values are still positive. Since we use annualized data, difference of magnitude between second moments of IP growth rate and sectoral stock returns is quite large. Maxima of sectoral volatilities ranges from 8181 to 59111, but maxima of squared positive shocks and negative shocks to IP growth rate is only 899 and 2367. Therefore, when we draw these three series together, most points of the asymmetric shocks shrink to the horizontal axis. This makes it hard to detect the relationship between sectoral volatilities and the asymmetric shocks. However, we can still notice that two peaks of squared negative shocks strongly influence sectoral volatilities. 

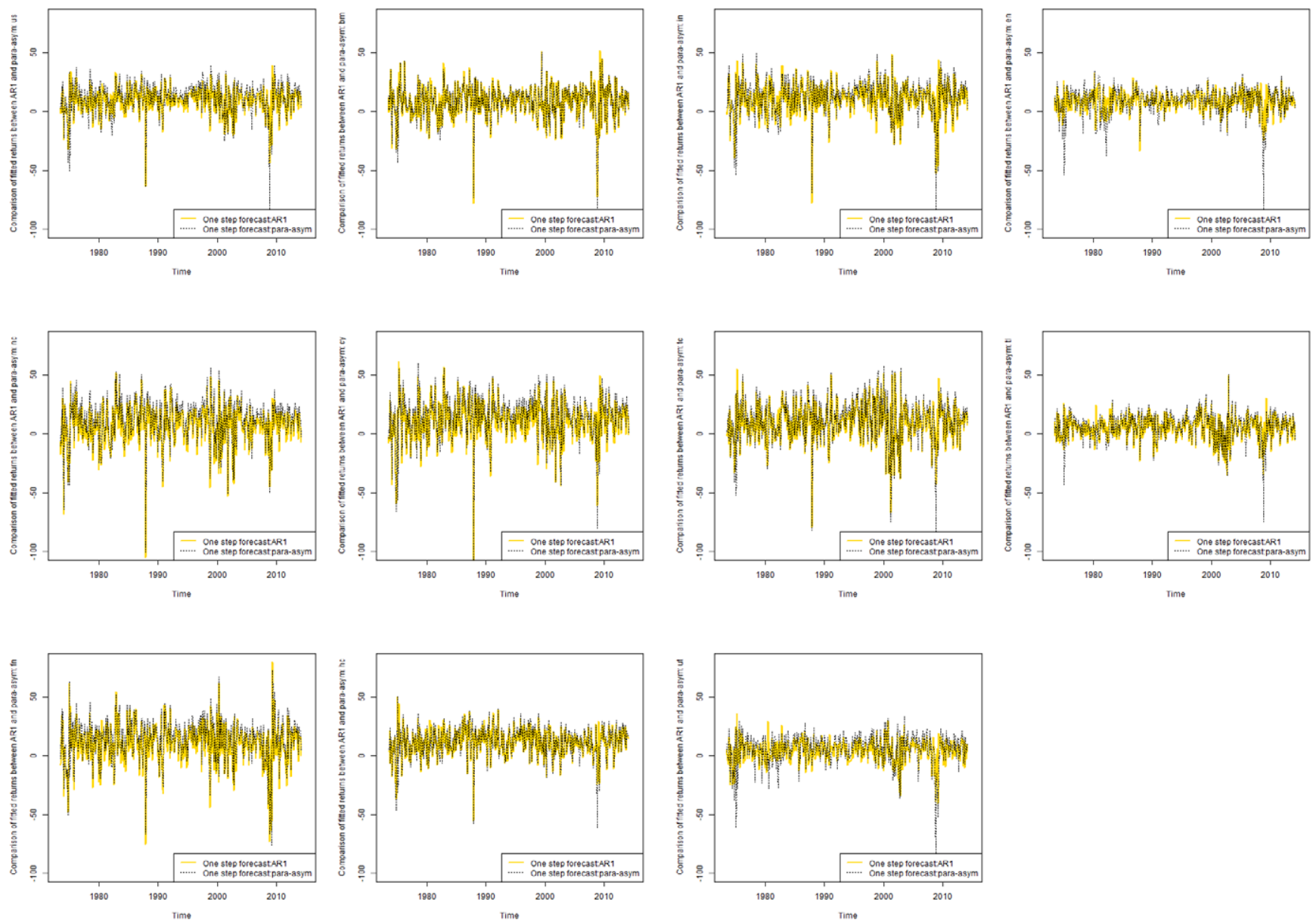

Figure 2: Comparison of fitted sectoral stock returns between AR (1) and parallel asymmetric model.

To summarize, business cycle has strong asymmetric effects on sectoral stock returns. Negative business cycle effects are generally stronger than the sectors' autoregressive effects. Negative shocks to the business cycle have strong spillover effects on CY, FN, HC, and IN. Good news on business cycle does not enhance existing sectoral stock volatilities, excepting for FN.

\section{Results for symmetric cross business cycle effect}

Table 7 summarizes estimation results of symmetric cross business cycle effect model. Our major interest falls on the estimated parameters of the risk items in the mean equation (9). Their estimates are listed in columns 2-3. In column 2, we find that some sectors exhibit a negative relationship between their returns and risk, like $\mathrm{NC}, \mathrm{CY}, \mathrm{HC}, \mathrm{IN}$, $\mathrm{EN}$, and UT. This result is quite different from much of the existing literature and contrary to most economic theories. If an asset has risk, investors do not want to hold it unless it provides a risk premium. Risk and premium should have positive relationship, since only high premium can compensate for high risk. Otherwise, no investor will consider a risky asset for investment purposes.

One reason for negative parameters for ARCH-M term may lie in the low frequency of the data. When averaging daily stock index to generate monthly data, volatility of the series diminishes largely.
Meanwhile, value of excess return will increase as it is accumulated during a month. Since the two variables develop toward opposite directions, the original positive relationship may reverse at some critical points.

Another reason for negative parameters for ARCH-M term may rest in the definition of risk. Generally, we use the second moment of a series to indicate its risk. However, when time of holding one asset increases, uncertainty of the asset's return will enlarge. This is the same expression that risk of holding the asset will enlarge. As a consequence, when frequency of a series falls, time of holding the asset should also is considered as a component of risk. In our model, time is not introduced as an explanatory variable, which will blur the relationship between risk and returns and produce some unusual phenomenon. However, since our interest focuses on business cycle effects, we will not cover the discussion about the time risk effect.

Column 3 lists the estimated parameters of business cycle risk for each sector. It turns out that business cycle risk will augment excess returns for some sectors, like $\mathrm{BM}, \mathrm{NC}, \mathrm{CY}, \mathrm{FN}$, and IN, but reduce them for other sectors, like US, HC, EN, TC, TL, and UT. This consequence can help us to predict sectoral excess returns when business cycle risk occurs. For example, one unit of business cycle change will increase CY's excess returns 2.367 times, but decrease UT's excess returns 1.403 times. 
Citation: Keran S, Prasad VB (2015) Asymmetric Business Cycle Effects on US Sectoral Stock Returns. Int J Econ Manag Sci 4: 289. doi:10.4172/21626359.1000289
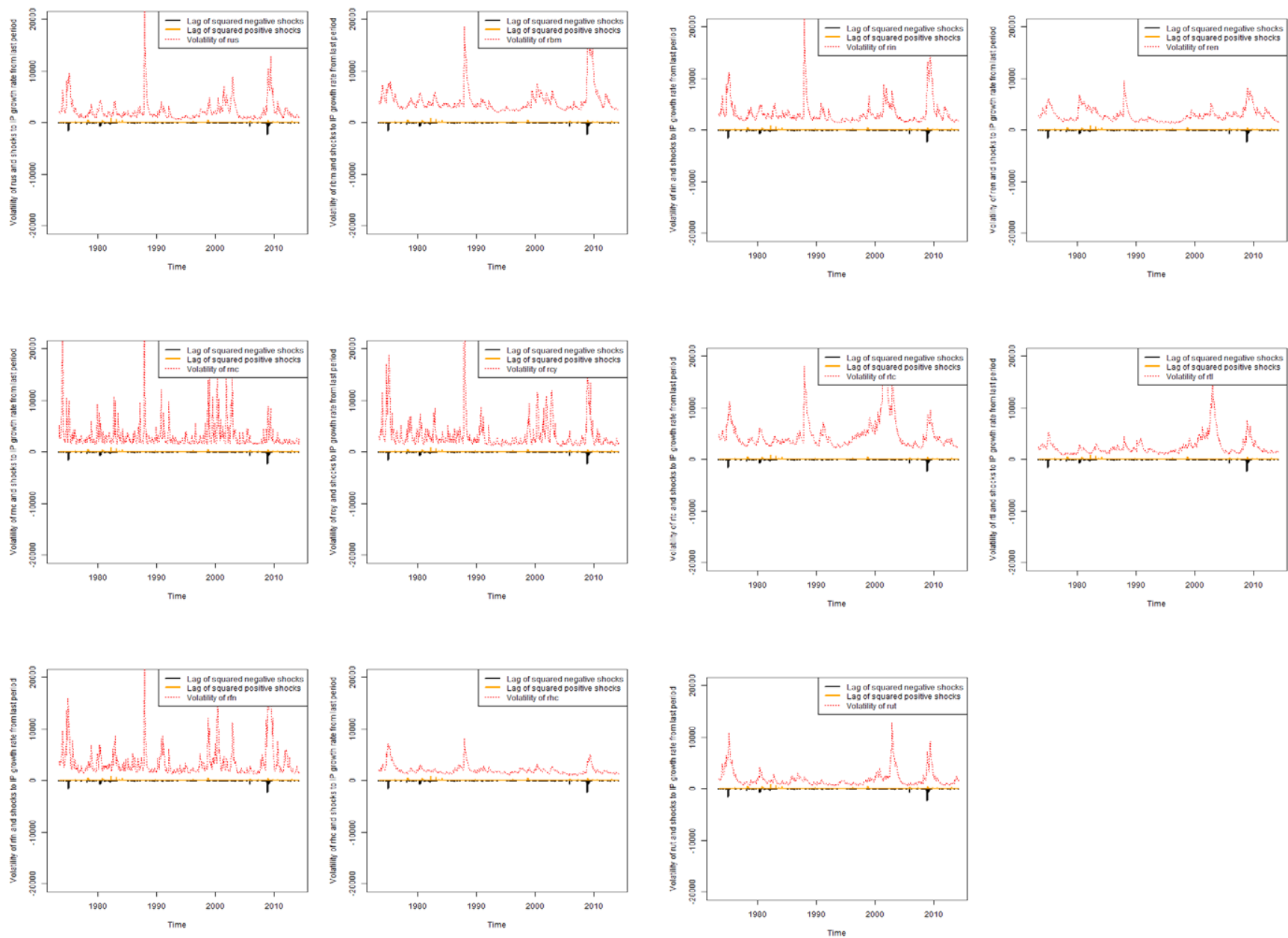

Figure 3: Plots of sectoral volatilities and asymmetric shocks to IP growth rate.

It is clear that business cycle risk has stronger effect on excess returns than sectors' own risk effect. For each sector, absolute value of $\delta_{\mathrm{i}}$ is greater than absolute value of $\theta_{\mathrm{i}}$. However, business cycle risk does not always have the same direction with sectors' own risk. For BM and FN both risks have positive effect. For HC, EN, and UT, both risks have negative effect. For the rest sectors, they influence excess returns oppositely. Therefore, business cycle risk can boost sector's own risk effect when they are toward the same direction but dominate sector's own risk effect when they are contrary.

\section{Results for asymmetric cross business cycle effect}

Table 8 summarizes the estimation results of asymmetric cross effect model. Parameters for sectoral stock returns' own risk terms, which are listed in column 2, still have same signs and magnitudes compared with symmetric model.

Columns 3 reports estimates of positive business cycle risk parameters $\delta_{i}^{p}$. Positive risk has positive effects on US, BM, NC, CY, FN, IN, and EN, and has negative effects on HC, TC, TL, and UT. Positive effects range from 0.048 on EN to 2.393 on CY. Negative effects range from -0.401 on HC to -1.27 on UT. Except US and EN, positive business cycle risk has stronger effects in absolute value than sector's own risk.

Columns 4 reports estimates of negative business cycle risk parameters $\delta^{n}$. Negative risk has positive effects on BM, CY, FN, and IN, and has negative effects on US, NC, HC, EN, TC, TL, and UT. Positive effects range from 0.112 on $\mathrm{BM}$ to 1.689 on CY. Negative effects range from -0.455 on NC to -1.785 on UT. Except BM, negative business cycle risk has stronger effects in absolute value than sector's own risk.

Obviously, business cycle risk effect is asymmetric, both in direction and magnitude. Some sectors are more sensitive to positive business cycle risk, like BM, NC, CY, FN, IN. Remaining sectors, like US, HC, EN, TC, TL, and UT, are more sensitive to negative business cycle risk. Both positive risk and negative risk have positive effects on $\mathrm{BM}, \mathrm{CY}, \mathrm{FN}$ and IN. Both of them have negative effects on HC, TC, TL, and UT. They have opposite effects on US, NC, and EN, while negative risk effects are negative and dominate positive risk effects which are positive. If combining all these asymmetric effects together, we can get similar symmetric effects as in results for symmetric cross business cycle effect. 
Citation: Keran S, Prasad VB (2015) Asymmetric Business Cycle Effects on US Sectoral Stock Returns. Int J Econ Manag Sci 4: 289. doi:10.4172/21626359.1000289

Page 11 of 13

\begin{tabular}{|c|c|c|c|c|c|c|}
\hline & (1) & (2) & (3) & (4) & (5) & (6) \\
\hline & $C_{i m}$ & $\theta_{i}$ & $\delta_{i}$ & $c_{i v}$ & $\alpha_{i}$ & $\beta_{i}$ \\
\hline \multirow[t]{2}{*}{ RUS } & 0.752 & 0.134 & -0.168 & 159.045 & $0.226^{*}$ & $0.731^{*}$ \\
\hline & -9.201 & -0.153 & -1.047 & -104.883 & -0.071 & -0.087 \\
\hline \multirow[t]{2}{*}{ RBM } & -9.43 & 0.155 & 0.375 & $382.687^{*}$ & $0.111^{*}$ & $0.803^{*}$ \\
\hline & -17.8 & -0.273 & -1.552 & -211.718 & -0.034 & -0.063 \\
\hline \multirow[t]{2}{*}{ RNC } & $21.462^{*}$ & $-0.361^{*}$ & 0.497 & $1780.467^{*}$ & $0.524^{*}$ & 0 \\
\hline & -10.89 & -0.172 & -1.353 & -243.659 & -0.094 & -0.054 \\
\hline \multirow[t]{2}{*}{ RCY } & 5.867 & -0.297 & 2.367 & $1452.697^{*}$ & $0.451^{*}$ & 0.161 \\
\hline & -13.383 & -0.259 & -1.5 & -677.54 & -0.087 & -0.233 \\
\hline \multirow[t]{2}{*}{ RFN } & -6.956 & 0.068 & 1.554 & $853.702^{*}$ & $0.412^{*}$ & $0.396^{*}$ \\
\hline & -12.95 & -0.187 & -1.353 & -272.144 & -0.105 & -0.124 \\
\hline \multirow[t]{2}{*}{ RHC } & 11.803 & -0.077 & -0.506 & 153.55 & $0.092^{*}$ & $0.837^{*}$ \\
\hline & -18.216 & -0.382 & -0.996 & -94.648 & -0.032 & -0.061 \\
\hline \multirow[t]{2}{*}{ RIN } & 6.212 & -0.098 & 0.728 & $308.541^{*}$ & $0.198^{*}$ & $0.732^{*}$ \\
\hline & -12.181 & -0.175 & -1.315 & -159.69 & -0.058 & -0.069 \\
\hline \multirow[t]{2}{*}{ REN } & 18.299 & -0.231 & -0.401 & $153.018^{*}$ & $0.108^{*}$ & $0.845^{*}$ \\
\hline & -12.913 & -0.225 & -1.263 & -74.008 & -0.03 & -0.039 \\
\hline \multirow[t]{2}{*}{ RTC } & 9.961 & 0.052 & -1.207 & $339.163^{*}$ & $0.115^{\star}$ & $0.819^{*}$ \\
\hline & -17.713 & -0.221 & -1.418 & -139.057 & -0.03 & -0.043 \\
\hline \multirow[t]{2}{*}{ RTL } & 4.142 & 0.074 & -0.869 & $120.242^{*}$ & $0.134^{*}$ & $0.819^{*}$ \\
\hline & -10.865 & -0.197 & -0.982 & -51.543 & -0.032 & -0.038 \\
\hline \multirow[t]{2}{*}{ RUT } & $19.008^{*}$ & -0.188 & -1.403 & $117.655^{*}$ & $0.168^{*}$ & $0.772^{*}$ \\
\hline & -9.237 & -0.182 & -0.923 & -42.356 & -0.038 & -0.043 \\
\hline \multicolumn{6}{|c|}{ Significance level: 0.1 ‘*’ } & \\
\hline
\end{tabular}

Note: 1. Numbers in braces are standard deviations. Some estimates are displayed as 0 since they are smaller than 0.00001 .

2. Estimation results of IP growth rate are the same as in parallel models and therefore are not listed here.

GARCH model of IP growth rate:

$\mathrm{r}_{\mathrm{gt}}=\mathrm{c}_{\mathrm{gm}}+\mathrm{a}_{\mathrm{g} 1} \mathrm{r}_{\mathrm{gt}-1}+\mathrm{a}_{\mathrm{g} 2} \mathrm{r}_{\mathrm{gt}-2}+\mathrm{a}_{\mathrm{g} 3} \mathrm{r}_{\mathrm{gt}-3}+\varepsilon_{\mathrm{gt}}, \varepsilon_{\mathrm{gt}}=\mathrm{v}_{\mathrm{gt}} \sqrt{\mathrm{h}_{\mathrm{gt}}}, \mathrm{v}_{\mathrm{gt}} \sim \mathrm{iid} \mathrm{N}(0,1)$

$\mathrm{h}_{\mathrm{gt}}=\mathrm{c}_{\mathrm{gv}}+\mathrm{a}_{\mathrm{g}} \varepsilon_{\mathrm{gt}-1}^{2}+\beta_{\mathrm{g}} \mathrm{h}_{\mathrm{gt}-1}$

GARCH model of sectoral stock returns:

$\mathrm{r}_{\mathrm{it}}=\mathrm{c}_{\mathrm{im}}+\theta_{\mathrm{i}} \sqrt{\mathrm{h}_{\mathrm{it}}}+\delta_{\mathrm{i}}^{\mathrm{p}} \sqrt{\mathrm{h}_{\mathrm{gt}}}+\delta_{\mathrm{i}}^{\mathrm{n}}{\sqrt{\mathrm{h}_{\mathrm{gt}}}}^{-}+\varepsilon_{\mathrm{it}}$,

$\varepsilon_{\mathrm{it}}=\mathrm{v}_{\mathrm{it}} \sqrt{\mathrm{h}_{\mathrm{it}}}, \mathrm{v}_{\mathrm{it}} \sim \mathrm{iid} \mathrm{N}(0,1)$ and independent of $\mathrm{v}_{\mathrm{gt}}$

$\mathrm{h}_{\mathrm{it}}=\mathrm{c}_{\mathrm{iv}}+\mathrm{a}_{\mathrm{i}} \varepsilon_{\mathrm{it}-1}^{2}+\beta_{\mathrm{i}} \mathrm{h}_{\mathrm{it}-1}$

Table 7: Estimation results of symmetric cross business cycle effect model.

Shocks to business cycle can exert their effects on sectoral stock returns through different channels. In parallel models, a shock to business cycle from last period plays a role in sectors' current volatilities. It appears in conditional variance equations and affects the second moment of sectoral stock returns directly. While in cross model, a shock to business cycle from last period first is transformed into current business cycle risk which then performs its function on current excess returns. In consequence, if there is a shock to business cycle, it can have spillover effects through sectors, it also can affect sectors' excess returns, depending on specific settings of a model.

Figure 4 illustrates one step ahead forecast under asymmetric cross business cycle effect model. Forecasted values can mimic observed values to some extent, especially for some extreme values. For US, $\mathrm{BM}$, and FN, positive forecast values are better. For NC, HC, EN, TC, TL, and UT, negative forecast values are better. For CY, two forecasts have equal quality. Based on this, if a shock to business cycle occurs, investors can predict its effects on next period sectoral excess returns and make appropriate adjustment.

\section{Conclusions}

In this paper, we use two models to discuss the asymmetric business cycle effects on US sectoral stock returns. Several conclusions can be drawn.

First, business cycle has asymmetric effects on mean of sectoral stock returns. Under symmetric parallel model, all sectors are procyclical. After introducing asymmetric effects, we find basic materials (BM), technology (TC), and telecommunication (TL) is pro-cyclical during depressions but are counter cyclical during expansions.

Second, shocks to business cycle have asymmetric spillover effects. Not all sectors, but consumer goods (NC), consumer service (CY), financials (FN), industrials (IN), and utility (UT) have their volatilities influenced by business cycle shocks. Moreover, spillover effects of business cycle mainly from negative shocks. Positive shocks to business cycle only spill over FN. 
Citation: Keran S, Prasad VB (2015) Asymmetric Business Cycle Effects on US Sectoral Stock Returns. Int J Econ Manag Sci 4: 289. doi:10.4172/21626359.1000289
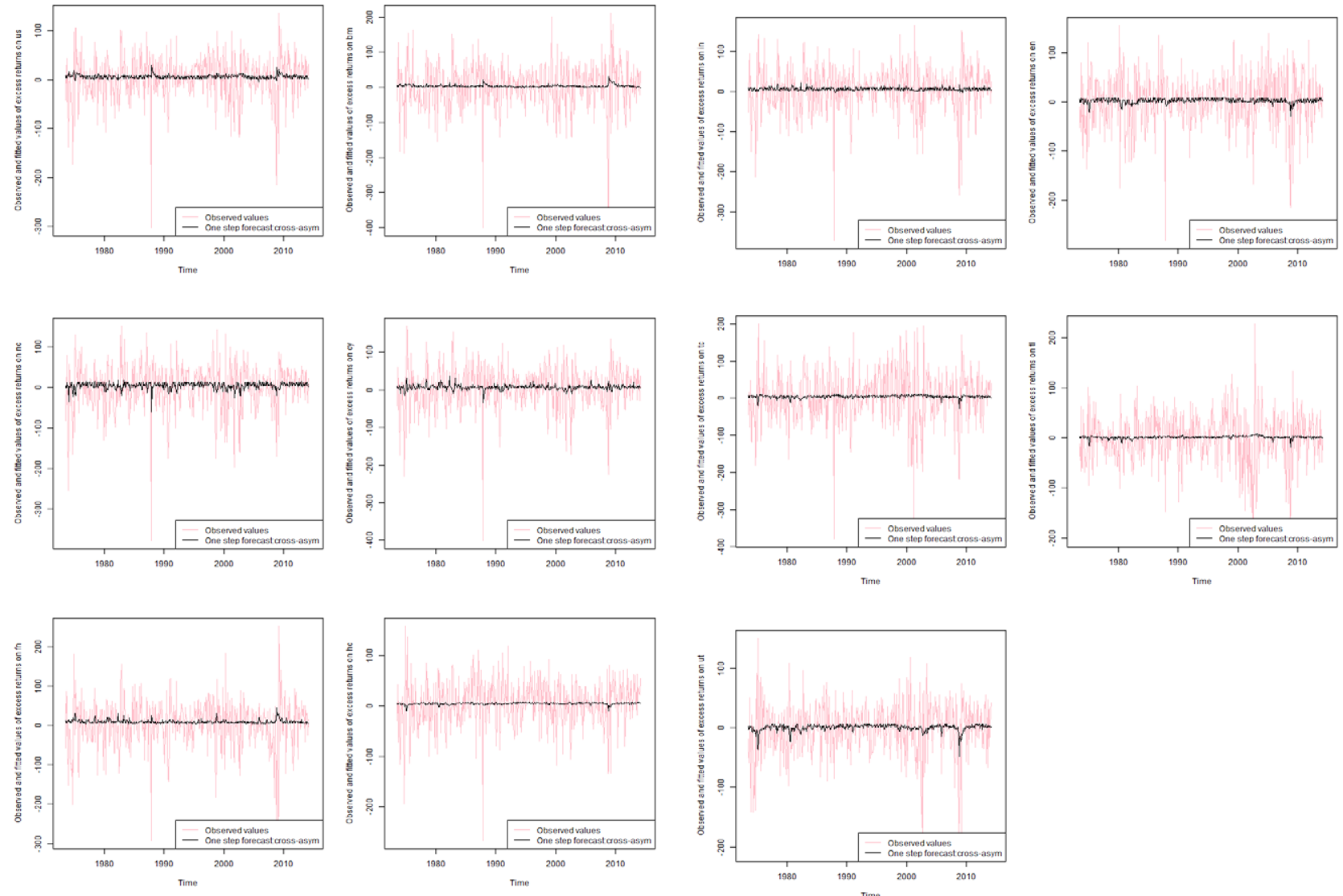

Figure 4: Fitted values of excess sectoral returns from asymmetric cross business cycle effect model.

\begin{tabular}{|c|c|c|c|c|c|c|c|}
\hline & (1) & (2) & (3) & (4) & (5) & (6) & (7) \\
\hline & $\mathrm{C}_{\mathrm{im}}$ & $\theta_{i}$ & $\delta_{i}^{p}$ & $\delta_{i}^{n}$ & $\mathrm{c}_{\mathrm{iv}}$ & $\alpha_{i}$ & $\beta_{i}$ \\
\hline \multirow[t]{2}{*}{ RUS } & 0.491 & 0.169 & 0.101 & -0.663 & 222.942 & $0.264^{*}$ & $0.671^{*}$ \\
\hline & -9.412 & -0.158 & -1.083 & -1.118 & -147.531 & -0.092 & -0.122 \\
\hline \multirow[t]{2}{*}{ RBM } & -10.684 & 0.181 & 0.582 & 0.112 & $397.985^{*}$ & $0.11^{*}$ & $0.8^{*}$ \\
\hline & -18.175 & -0.281 & -1.584 & -1.613 & -222.865 & -0.035 & -0.066 \\
\hline \multirow[t]{2}{*}{ RNC } & $22.27^{*}$ & $-0.322^{*}$ & 0.617 & -0.455 & $1705.481^{*}$ & $0.541^{*}$ & 0.006 \\
\hline & -10.532 & -0.163 & -1.283 & -1.364 & -215.776 & -0.094 & -0.043 \\
\hline \multirow[t]{2}{*}{ RCY } & 4.333 & -0.224 & 2.393 & 1.689 & $1281.754^{*}$ & $0.448^{*}$ & 0.218 \\
\hline & -13.247 & -0.284 & -1.813 & -1.944 & -773.048 & -0.088 & -0.276 \\
\hline \multirow[t]{2}{*}{ RFN } & -7.777 & 0.081 & 1.81 & 1.336 & $853.83^{*}$ & $0.416^{*}$ & $0.392^{*}$ \\
\hline & -13.008 & -0.188 & -1.408 & -1.413 & -267.709 & -0.105 & -0.123 \\
\hline \multirow[t]{2}{*}{ RHC } & 11.842 & -0.077 & -0.401 & -0.612 & 153.109 & $0.092^{*}$ & $0.837^{*}$ \\
\hline & -18.078 & -0.379 & -1.026 & -1.027 & -95.669 & -0.032 & -0.062 \\
\hline \multirow[t]{2}{*}{ RIN } & 5.088 & -0.056 & 1.079 & 0.158 & $369.938^{*}$ & $0.204^{*}$ & $0.707^{*}$ \\
\hline & -12.524 & -0.187 & -1.34 & -1.381 & -191.817 & -0.061 & -0.083 \\
\hline \multirow[t]{2}{*}{ REN } & 15.569 & -0.166 & 0.048 & -0.989 & $166.642^{*}$ & $0.105^{\star}$ & $0.841^{*}$ \\
\hline & -13.443 & -0.243 & -1.296 & -1.318 & -82.192 & -0.031 & -0.043 \\
\hline \multirow[t]{2}{*}{ RTC } & 8.302 & 0.078 & -0.854 & -1.518 & $353.538^{*}$ & $0.118^{*}$ & $0.813^{*}$ \\
\hline & -17.647 & -0.22 & -1.473 & -1.461 & -145.549 & -0.031 & -0.045 \\
\hline \multirow[t]{2}{*}{ RTL } & 3.743 & 0.083 & -0.716 & -1.033 & $121.062^{*}$ & $0.132^{*}$ & $0.819^{*}$ \\
\hline & -10.949 & -0.199 & -1.013 & -1.018 & -51.821 & -0.032 & -0.038 \\
\hline \multirow[t]{2}{*}{ RUT } & $20.116^{*}$ & -0.189 & -1.27 & $-1.785^{*}$ & $116.696^{*}$ & $0.171^{*}$ & $0.77^{*}$ \\
\hline & -9.276 & -0.181 & -0.936 & -0.983 & -41.882 & -0.039 & -0.043 \\
\hline
\end{tabular}

Note: 1 . Numbers in braces are standard deviations. Some estimates are displayed as 0 since they are smaller than 0.00001.

2. Estimation results of IP growth rate are the same as in parallel models and therefore are not listed here.

Table 8: Estimation results of the asymmetric cross business cycle effect model. 
Citation: Keran S, Prasad VB (2015) Asymmetric Business Cycle Effects on US Sectoral Stock Returns. Int J Econ Manag Sci 4: 289. doi:10.4172/21626359.1000289

Third, business cycle risk has asymmetric effects on excess returns on sectoral stock indices. Positive risk and negative risk have positive effects on BM, CY, FN, and IN, have negative effects on health care (HC), TC, TL, and UT, and have opposite effects on US, NC, and oil and gas (EN). Focusing on absolute value, positive risk has stronger effects on $\mathrm{BM}, \mathrm{NC}, \mathrm{CY}, \mathrm{FN}$, and IN, while negative risk has stronger effects on US, HC, EN, TC, TL, and UT.

Fourth, business cycle effects are generally stronger than own sectoral effects. Whether they are effects on means of sectoral stock returns, effects on volatilities of sectoral stock returns, if any, or effects on excess sectoral returns, whether they are symmetric or asymmetric, they almost always possess larger estimated parameters compared to corresponding sectoral effects.

Finally, shocks to business cycle influence sectoral indices through two channels. In the parallel effect model, business cycle shocks exert their effect directly on the volatility of sectoral stock returns. In the cross effect model, business cycle shocks first are passed on to conditional variances, which in turn play a role in affecting excess sectoral stock returns through their square root.

Some questions also emerge in this practice. For example, why do the ARCH-M terms in cross effect model have negative parameters, and how will the ARCH-M terms affect the excess sectoral returns if conditional variances of sectoral indices are influenced by business cycle shocks. We will follow up these questions in future research.

\section{References}

1. Fama EF, French KR (1989) Business conditions and expected returns on stocks and bonds. Journal of Financial Economics 25: 23-49.

2. Campbell SD, Diebold FX (2009) Stock returns and expected business conditions: Half a century of direct evidence. Journal of Business \& Economic Statistics 27: 266-278.

3. Daniel K, Torous W (1995) Common stock returns and the business cycle. Center for Research in Security Prices, Graduate School of Business, University of Chicago pp:100.

4. Agbloyor EK, Joshua A, Charles KDA, Alfred Y (2012) Exploring the causality links between financial markets and foreign direct investment in Africa. Research in International Business and Finance 28: 113-134.

5. Lee CC, Chien MS, Lin TC (2012) Dynamic modelling of real estate investment trusts and stock markets. Economic Modelling 29: 395-407.
6. Han TS, Shen CH (2007) The effects of bonus systems on firm performance in Taiwan's high-tech sector. Journal of Comparative Economics 35: 235-249.

7. Kutan AM, Muradoglu G, Sudjana BG (2012) IMF programs, financial and real sector performance, and the Asian crisis. Journal of Banking \& Finance 36: 164-182.

8. Mohanty S, Nandha M, Bota G (2010) Oil shocks and stock returns: The case of the Central and Eastern European (CEE) oil and gas sectors. Emerging Markets Review 11: 358-372.

9. Salaber $J(2007)$ The determinants of sin stock returns: Evidence on the European market in Paris. Finance International Meeting AFFI-EUROFIDA Paper.

10. Arouri MEH (2011) Does crude oil move stock markets in Europe? A sector investigation. Economic Modelling 28: 1716-1725.

11. Arouri MEH, Jouini J, Nguyen DK (2011) Volatility spill overs between oil prices and stock sector returns: Implications for portfolio management. Journal of International Money and Finance 30: 1387-1405.

12. Arouri MEH, Nguyen DK (2010) Oil prices, stock markets and portfolio investment: Evidence from sector analysis in Europe over the last decade. Energy Policy 38: 4528-4539.

13. Nandha M, Faff R (2008) Does oil move equity prices? A global view. Energy Economics 30: 986-997.

14. Jayasinghe $P$, Tsui $A K$ (2008) Exchange rate exposure of sectoral returns and volatilities: Evidence from Japanese industrial sectors. Japan and the World Economy 20: 639-660.

15. Balli F, Balli HO (2011) Sectoral equity returns in the Euro region: Is there any room for reducing portfolio risk? Journal of Economics and Business 63: 89-106.

16. Sehgal S, Jain S (2011) Short-term momentum patterns in stock and sectoral return: Evidence from India. Journal of Advances in Management Research 8: $99-122$.

17. Berdot JP, Goyeau D, Léonard J (2006) The Dynamics of Portfolio Management: Exchange Rate Effects and Multisector Allocation. International Journal of Business 11: 188-209.

18. Choi MS, Zéghal D (2002) Exchange rate exposure and the value of the firms: Faculty of Administration, University of Ottawa.

19. Koutmos G, Martin AD (2007) Modeling time variation and asymmetry in foreign exchange exposure. Journal of Multinational Financial Management 17: 61-74.

20. Holt MT, Aradhyula SV (1998) Endogenous risk in rational-expectations commodity models: A multivariate generalized ARCH-M approach. Journal of Empirical Finance 5: 99-129.

21. Polasek W, Ren L (2000) A multivariate GARCH-M model for exchange rates in the US, Germany and Japan. Springer 355-363. 